GaRCía GonzÁLEz, Guillermo. Régimen jurídico de los técnicos de prevención de riesgos laborales: obligaciones, garantías y responsabilidades, Dykinson, Madrid, 2019, 249 pp., ISBN 9788413244952.

\author{
http://dx.doi.org/10.18543/ed-67(2)-2019pp587-589
}

Quisiera comenzar esta recensión manifestando la satisfacción que supone para mí reseñar la reciente publicación del profesor García González, gran experto iuslaboralista con especial dedicación y larga trayectoria en el ámbito de la seguridad y salud laboral.

Se encuentra el lector ante la primera monografía que se dedica de forma exclusiva al análisis jurídico de los técnicos de prevención de riesgos laborales. Publicada por la prestigiosa editorial jurídica Dykinson, Régimen jurídico de los técnicos de prevención de riesgos laborales: obligaciones, garantías y responsabilidades aborda de forma integral los principales elementos que, desde una perspectiva jurídica, conforman el especial estatus de los trabajadores con funciones preventivas.

La relevancia que los técnicos de prevención tienen en nuestro modelo de prevención de riesgos laborales, sus especiales funciones y su singular posición en la empresa, convierten a este colectivo de trabajadores en uno de los pivotes sobre los que se articula nuestro derecho de prevención de riesgos laborales. Esta relevancia, unida a la escasez de estudios sobre la materia, convierte a la obra que se analiza en un estudio esencial para comprender el alcance y contenido del derecho de la seguridad y salud en nuestro país.

El propio título de la monografía avanza los puntos básicos sobre los que se articula el análisis. De este modo, las obligaciones, las garantías y las responsabilidades de los prevencionistas constituyen los componentes nucleares del estudio, que se estructura en cinco capítulos.

Los dos primeros capítulos se ocupan de examinar de forma detallada el marco obligacional de los técnicos de prevención. La ausencia de regulación expresa y sistemática sobre ese punto es resuelta de forma brillante por el autor. En este sentido, y partiendo de distintas normas, criterios técnicos y resoluciones judiciales y administrativas, el estudio elabora una sistematización de las principales obligaciones de los técnicos de prevención. Para ello, el autor parte de las escasas 
obligaciones configuradas expresamente por la Ley 31/1995, de Prevención de Riesgos Laborales, a las que denomina supraobligaciones instrumentales. Junto con ellas, y con base en las competencias atribuidas reglamentariamente, se desgranan uno a uno todos los posibles deberes que pueden corresponder a los técnicos de prevención. Presentadas de este modo las obligaciones, se sostiene que estas pueden modularse en virtud de la autonomía de las partes. En relación con este extremo, se mencionan el plan de prevención, el contrato de trabajo (en sentido amplio) y la autonomía colectiva como fuentes de concreción de las obligaciones de los técnicos de prevención. El constructo que conforma el estudio en este apartado resulta coherente y dota de sistematicidad a una materia que, desde el punto de vista de nuestro ordenamiento jurídico positivo, carece de ella.

El tercer capítulo examina de forma profusa y pormenorizada las distintas garantías que la Ley 31/1995, de Prevención de Riesgos Laborales otorga a los técnicos de prevención. Especialmente relevante se presenta la delimitación subjetiva de las garantías, analizando el estudio distintos supuestos controvertidos, así como su interpretación jurisprudencial. Similar interés se deriva del análisis que se efectúa de las concretas garantías de los técnicos de prevención desde un punto de vista material u objetivo. La traslación que hace el legislador de las garantías propias de la representación legal de los trabajadores, extendiéndolas a los técnicos de prevención, suscita distintos conflictos interpretativos que son planteados y resueltos en este capítulo de forma sobresaliente.

Los dos últimos capítulos de la monografía se ocupan de examinar los distintos tipos de responsabilidades en los que pueden incurrir los técnicos de prevención. Se distingue a estos efectos la dimensión pública y privada de la responsabilidad para sistematizar el complejo diseño jurídico que nuestro ordenamiento dibuja en lo que atañe a las responsabilidades preventivas. Desde el ámbito público, se reflexiona sobre la inexistente responsabilidad administrativa de los técnicos y acerca de su responsabilidad penal. Atendiendo al ámbito privado, la responsabilidad civil y la responsabilidad disciplinaria laboral son examinadas con detenimiento y precisión, entresacando los principales problemas aplicativos que este tipo de responsabilidad comportan. Desde la óptica civil, se realiza una completa panorámica de los distintos supuestos en que este tipo de responsabilidad puede concurrir en los técnicos, distinguiendo su alcance en función de si la responsabilidad es frente a su empresario o frente a terceros, y dentro de la primera de las situaciones, diferenciando en atención a quien es el empleador del técnico, servicio de prevención ajeno u otro tipo de empresario. Respecto al ámbito laboral, mención especial merece el completo estudio que el autor realiza del convenio colectivo sectorial de los servicios de prevención ajenos.

En esta parte del estudio, el texto evidencia un claro dominio de la materia por parte de su autor, insertándose en caminos que se alejan del ámbito estrictamente laboral para profundizar en elementos propios del 
ámbito civil y del penal. Ambos capítulos cuentan con una prolija jurisprudencia que va ilustrando el discurso y las distintas conclusiones que se van derivando del análisis. También se deslizan interesantes propuestas de lege ferenda, algunas de ellas no exentas de cierta polémica, pero sólidamente fundamentadas con argumentaciones jurídicas de peso.

La obra destaca por su facilidad y agilidad en su lectura, sin que ello suponga en ningún momento menoscabar la calidad y rigurosidad del análisis jurídico. La bibliografía empleada por el autor es extensa y recoge las principales aportaciones doctrinales que se han realizado sobre el objeto de estudio. El rigor científico que demuestra el autor se acompaña de una practicidad en su análisis, que se evidencia en la numerosísima jurisprudencia que jalona todo el estudio; jurisprudencia que recoge los últimos pronunciamientos judiciales en todos los concretos aspectos que la obra aborda.

Se trata, en definitiva, de una monografía con un indudable interés teórico y práctico, que viene a cubrir de forma integral el vacío que hasta ahora existía en la doctrina iuslaboralista sobre una figura clave en nuestro sistema preventivo, como son los técnicos de prevención de riesgos laborales.

Carmen Salcedo Beltrán ${ }^{1}$

Profesora Titular de Derecho del Trabajo y Seguridad Social

Universidad de Valencia

${ }^{1}$ ORCID: https://orcid.org/0000-0002-6529-2396. ResearcherID: Z-5983-2019. 


\title{
García GonzÁlez, Guillermo. Régimen jurídico de los técnicos de prevención de riesgos laborales: obligaciones, garantías y res- ponsabilidades, Dykinson, Madrid, 2019, 249 pp., ISBN 9788413244952.
}

\author{
http://dx.doi.org/10.18543/ed-67(2)-2019pp587-589
}

\section{Copyright}

Estudios de Deusto es una revista de acceso abierto, lo que significa que es de libre acceso en su integridad. Se permite su lectura, la búsqueda, descarga, distribución y reutilización legal en cualquier tipo de soporte sólo para fines no comerciales, sin la previa autorización del editor o el autor, siempre que la obra original sea debidamente citada y cualquier cambio en el original esté claramente indicado

Estudios de Deusto is an Open Access journal which means that it is free for full access, reading, search, download, distribution, and lawful reuse in any medium only for non-commercial purposes, without prior permission from the Publisher or the author; provided the original work is properly cited and any changes to the original are clearly indicated. 